\title{
Lingua and culture study research on indirect communication cognitive metaphor
}

\author{
Zhanna Ospanova - Karima Tolybayeva - Saule Nurkenova - Kulyash \\ Duisekova - Gaukhar Baltabayeva
}

DOI: 10.18355/XL.2020.13.02.13

\begin{abstract}
In the linguistic field, the problem of the metaphor - both as a process that creates new meanings of language expressions in the course of rethinking them and as a ready-made metaphorical meaning - has been considered for a long time rather as a stylistic tool or artistic device. Less commonly, a metaphor was considered as a means of nomination, even less often - as a way to create a linguistic picture of the world, resulting from cognitive manipulation of the meanings already in the language with the aim of creating new concepts. The latter applies especially to those areas of reflection of the reality are not given in direct sensation. The relevance of this research is due to the fact that, at the modern stage of the development of linguistics, a new interpretation of facts becomes a new reality. In this case, it can be argued that new approaches in modern linguistics also lead to the discovery of new realities. Objects seen from a new angle reveal new properties. This research paper reviews this issue from language and cultural aspects, and specifically gives attention to the cognitive metaphors of indirect communication. The authors use theoretical approaches to the study of this issue and based on empirical analyses, justify the selected types of metaphors.
\end{abstract}

Key words: cognitive metaphor, metaphorizing, indirect communication, stylistically reduced vocabulary

\section{Introduction}

Cognition of the culture of a nation, the characteristics of its national character, mores, its spiritual disposition is inconceivable without knowledge of its language. Language is not merely an explication, a materialization of hidden ideal mental and thought processes. These processes are inseparable from the language; they are essentially linguistic.

At all times, language has been the adequate characterizing identification of a society, its culture, although the waves of "philological interest" in the problem of "language - culture - mentality" were different in both intensity and wavelength. The current situation can be characterized by the words: "Back to Humboldt," who, as you know, considered that language as an instrument of people's thoughts and feelings is the basis of genuine language research.

However, the roots of modern lingual culturology can be found in scientific sources from the time of Ancient Greece, and in the works of M.V. Lomonosov. But, of course, the works of V. von Humboldt played a fundamental, central role in the formation and development of scientific concepts, one way or another connected with the study of the relationship between language and culture.

The research of the scientist about the "linguistic vision" and the "internal form of the language" is fundamental to linguistic and cultural studies.

The hypothesis of linguistic relativity of Sepir-Whorf, the epistemological teachings of L. Wittgenstein and the development of the ideas of the scientist by the Neo-Humboldtians, including J. L. Weisgerber, the works of E. Benvenist, K. LevyStrauss, and V. Pike, these are merely few examples of a long list of the names of

XLinguae, Volume 13 Issue 2, April 2020, ISSN 1337-8384, ISSN 2453-711X 
foreign researchers who have made a significant contribution to the development of linguacultural science.

We cannot fail to note the important contribution of researchers, such as F. I. Buslaev, A. N. Afanasyev and, of course, A. A. Potebnya, who paid much attention to the development of the science of the links between language and culture.

In recent years, linguacultural study as a relatively new scientific brunch has passed the stage of formation and thanks to the work of such famous researchers as E. M. Vereshchagin, V. G. Kostomarov, Yu. S. Stepanov, V. N. Telia, N. F. Alefirenko, G. M. Vasilieva, S. G. Vorkachev, E. I. Zinoviev, V. I. Karasik, V. V. Krasnykh, V. A. Maslova has become not only a "notable and popular" scientific direction but also a kind of "integrator" of scientific searches devoted to the problems of the interaction of language and culture.

In this specific research, we study language and culture study on indirect communication of cognitive metaphors, for that, we need to clarify what is a cognitive metaphor and metaphorizing, as well as what is indirect communication.

The study of metaphorizing processes is the focus of many sciences, many directions in linguistics, but primarily in the circle of such anthropocentric ones as cognitive linguistics and lingua-culturology. The relevance of the study of metaphor stems from the universal mechanism of metaphorical meaning formation and functioning, in which characteristic features, ways of knowing the world, oneself in this world, as well as the interaction of language, consciousness, and culture is manifested. It is in the metaphor that the systemic linguistic-creative ability to conceptualize the reality given in sensations is manifested while giving the universal character of conceptualization national-specific features. A variety of research approaches, very contradictory results, lack of unity on the most important issues of metaphor study, and especially on the problems of cultural interpretations give particular relevance to the study of the basic processes of metaphorizing and the metaphorical models characterizing them.

The significance of the research is also determined by the attention of linguistics at the present stage of its development to the problem of the nature and functions of metaphors as cognitive means of language, as well as an understanding of metaphors as a culturally marked layer of language that reflects perception and, accordingly, represents a powerful tool for influencing the emotions and consciousness of a person, as well as an instrument capable of fixing certain samples of objects and phenomena in language and speech.

If we can make a quick look at the diachrony of metaphors, we observe that the history of the study of metaphor as an object of scientific research is of independent scientific interest, and the results of such studies are both highly specialized (in the aspect of metaphor ology) and of a broad interdisciplinary significance (including lingual- philosophical, linguacultural, psycholinguistic, etc.)

The authors of this study take the necessity of considering previous experience in modern research seriously. At the same time, the accumulated experience of historical comprehension allows us to dwell on those approaches that have developed in the scientific community that is most significant for the chosen direction of or research.

The centuries-old history of research is usually associated with the name of Aristotle as the founder of the scientific study of metaphor. Although other ancient authors are mentioned, for example, the speaker Isokrat, a student of the sophists Gorgias and Prodik, who indicated that the essence of the metaphor consists in transferring the name of one object to another, which was reflected in the name metafora (meta - through and feren - transfer) (Akhmadeeva 2006).

The purpose of the research is to determine the cognitive potential of figurative metaphor as an instrument for forming a picture of the world based on descriptions of characteristics on the example of the English language. Achieving this goal involves solving the following research questions: 
What is a description of the main trends in a linguacultural study of cognitive metaphor? What is the study of indirect communication?

The research methods were determined by the goal and the advanced tasks of this research. The study used methods of semantic-stylistic analysis, comparative analysis, as well as methods of structural, component, and contextual analysis.

\section{Discussion}

By answering the research question about cognitive metaphor, we need to identify what is a metaphor by itself. A metaphor is a powerful tool for the formation of new concepts, i.e., reflection in the linguistic form of new knowledge about the world - empirical, theoretical, or artistic development of reality.

Therefore, the metaphor performs a conceptual function in the language, "which is based on the ability of the metaphor to form new concepts, based on already formed concepts. The metaphor most fully fulfills the conceptual role in the designation of "non-essential entities," i.e. if necessary, in the designation of objects of the "invisible world" (Bizheva 2000). In this understanding, the conceptual metaphor approaches a cognitive one.

Fundamentally important for a conceptual metaphor is its role in the conceptualization of certain semantic zones. Such metaphors are relevant from the point of view of a native speaker (Moskvin 1997). A metaphor is a kind of transformation of the world in human consciousness. One of the most important means of such a transformation, the researchers believe, is a metaphorical model that allows us to present a complex problem as a simple one. Modern ideas about metaphor are based on the idea of imagery and metaphoricity as an integral property of human cognition and thinking.

The fundamental role in the formation of such an approach to the study of metaphor was played by J. Vico, I. Kant, V. von Humboldt, A. A. Potebnya, F. Nietzsche. In the works of these researchers, we can find valuable observations that testify to their understanding of the inextricable link between language and thinking, which is most clearly manifested in the process of metaphorizing, about the special role of metaphor in mastering reality, where rational cognition became possible thanks to a kind of "metaphorical bridge" thrown from the psycho somatosensory processes of perception to logical comprehension. Representations of language as a creative activity, observation of the role of metaphor in the processes of myth-making, and aesthetic/artistic mastery of reality led to the understanding of the meaning of metaphor in the formation and expression of a certain worldview, such as thinking and culture, which to some extent can be considered the beginning of the consideration of metaphor in lingua-culturological aspect.

The originality of modern approaches to the description of metaphorizing processes is associated primarily with the lack of not only a unified concept for their study, but also with a frightening variety of research methods and principles, and the appearance of more and more new approaches. Moreover, it is also linked to affecting and rethinking the basic parameters and mechanisms of metaphorizing.

According to most researchers, the priority areas of modern metaphor studies are somehow related to cognitive science. Its focus on the study of processes of cognition and understanding of the world determines the direction of most metaphor oriented studies, from analysis and interpretation of metaphorical statements to the study of world understanding mechanisms, the features of structuring knowledge as mental systems in the human mind, up to the concept of metaphor as a kind of "key" that opens the "door" into the conceptual sphere of a separate linguistic personality, society, nation, humanity as a whole. The special nature of the metaphor is the "ubiquitous principle of language" (Richard, 1990), which allows us to consider it as a 
special, dominant subject of study in linguistic, cognitive science, and linguaculturology.

Among the many linguistic approaches to the study of metaphors, we are interested in those in which the lingua-culturological aspect of the study is present to one degree or another. The same aspect determined the nature of the historical excursion, and the features of the review of non-linguistic- philosophical, logical, psychological approaches that significantly affect the formation of the linguacultural direction in the study of metaphorizing processes.

Among the numerous linguistic classifications, let us dwell on those that aroused the greatest attention among metaphor researchers and which, to one degree or another, correlate with linguistic and cultural studies.

One of the basic classifications for modern lingua-metaphorology is the classification of G. N. Sklyarevskaya, who presents 11 aspects of the study of cognitive metaphors: they are semasiological, onomasiological, epistemological, logical, linguistic proper, linguistic-stylistic, psycholinguistic, expressiological, linguistic-literary lexicographical (Sklyarevskaya, 2009). Another widely known classification of metaphors can be found in the study of V. K. Kharchenko, who describes 15 functions of a metaphor and their analysis (Kharchenko, 2002). In the circle of numerous classifications of metaphor functions - according to the observations of S. A. Akhmadeeva, there are 60 of them (Akhmadeeva, 2006) fruitful attempts seem to be those in which their number is minimized on the basis of identifying the main ones. So, V.P. Moskvin defined three main functions of the metaphor - nominative, cognitive, and figurative, although highlighting certain varieties in each of them (Moskvin 1991). Despite all the variety of modern approaches to the study of metaphor, we cannot fail to note the work of supporters of cognitive analysis of metaphorizing processes, in which the metaphor is considered " a linguistic phenomenon that reflects the basic cognitive process" (Petrov, 1990). This approach is primarily associated with the fundamental work of J. Lakoff and M. Johnson, in which, based on a thorough analysis of basic, conceptual metaphors, it is concluded that they play a huge role in the processes of thinking and communication (J. Lakoff, M. Johnson, 1980).

Figurative (metaphorical) models form a conceptual system, and these figurative schemes permeate the entire mechanism of speech, speech production, and all spheres of speech activity. The following data of foreign researchers are very peculiar in this regard. In television debates and television news, speakers use one metaphor for every 25 words (Graesser, Long, - Mio, J. 1989), and 1.80 original and 4.08 generally accepted, "language" metaphors (Pollio, Barlon, Fine, Pollio, 2007) are used per minute of conversation.

Among the various linguistic approaches to the study of metaphor, which are basic for the linguacultural aspect of the study, the structural-semantic one plays a key role. At the same time, the modern principles and features of this approach, of course, are based on the philosophical, logical, and psychological aspects of the study of metaphor (results and processes of metaphorizing), which were presented earlier in a condensed form. The role of a kind of bridge from these directions to the structuralsemantic approach has been played by studies that are somehow related to the cognitive approach. "In accordance with cognitive theory, the essence of metaphorizing is to map the cognitive space of a source into the cognitive space of an object" (English-Russian Dictionary of Linguistics and Semiotics 2001). From a cognitive point of view, the process of metaphorizing is the transfer of some part of the structure of knowledge from the source to the goal area - the conceptual structure that the process of cognitive mapping is directed to when forming the metaphor.

This work is devoted to the study of lingua and cultural aspects of cognitive metaphors in indirect communication to its mechanisms of constructing imagery, the analysis of the role of metaphor in the formation of a picture of the world, as well as 
the description of the semantic and stylistic properties of metaphor in English language. This problem turned out to be connected with a whole range of global linguistic problems, such as language and culture, language and thinking, cognitive aspects of semantics, etc., which determined the structure of the work.

Language reflects the reality surrounding us with a system of isomorphic means: through a person's attitude to the world around him, as well as through the perception and description of this world in such places as logical understanding and emotional assessment. The role of cognitive metaphor in giving emotionality to work cannot be overestimated. As a certain type of tropes, a metaphor is studied in poetics, as a source of new meanings of words - in lexicology, as a special type of speech use - in pragmatics, as an associative mechanism and an object of interpretation and perception of speech - in psycholinguistics, as a way of thinking and cognition, the metaphor is described in logic and philosophy. All this leads to the existence of a number of approaches to the study of metaphor. These represent such directions in the theory of metaphor as substitutional, comparative, interactionist, cognitive, etc.

The existence of a huge number of directions that study the essence of metaphors can be explained by the variety of this linguistic phenomenon, various functions, and types of metaphors. The task of constructing a theory of metaphor, which has sufficient explanatory power, cannot be solved within the framework of linguistics and requires entering the field of human cognitive processes.

Cognitive theory, but at the center of human research, linked the understanding of metaphor with the mental processes that accompany the generation and perception of speech. The cognitive metaphor is presented as a mental and linguistic mechanism, consisting of the interaction of two entities, which leads to new knowledge about the surrounding reality.

As indicated above, there are numerous definitions of the phenomenon of metaphor. For this study, we set up relevant goals and objectives. It was defined as a mental and linguistic mechanism, consisting of transferring the name from one object to another and, as a result finding a common attribute in them, by analogy, or similarity, which is considered as one of the main pathways.

A lot of work has been written about the metaphor. Not only scientists thought about it, but also its creators themselves - writers, poets, artists. In other words, everyone who has ever been interested in issues of language, culture, and thinking, considered it his duty to speak out and leave the descendants an opinion on the nature and significance of the metaphor phenomenon.

Interest in the cognitive metaphor arose long before our era when the metaphor was seen as a means of decorating speech. At the same time, the approach to the study of this linguistic phenomenon changed depending on the state of the scientific worldview. Thus, long before our era, scientists had different attitudes to the emotional power of cognitive metaphor: they considered it, after Aristotle and Quintilian, the main means among the tropes. They saw in it only an artistic, poetic value, and they followed Cicero to explain the origin of the metaphor as a result of borrowing from the native language (Antique,1936).

Subsequently, the approach to the study of cognitive metaphor changed, which was associated with the emergence of new methods and theories in the study of linguistic meanings. In the framework of cognitive linguistics, which stood out in an independent direction, the metaphor began to be actively studied as a way of representing knowledge in a language. The emergence of a metaphor is closely related to the process of the formation of concepts, which occurs in the human mind and is characterized as a dialectically complex reflection of reality.

Interest in the metaphor is due to the fact that, based on its many definitions, they see in it a "key" to understanding and cognizing the world. Therefore, the desire for 
its comprehensive study and, accordingly, the multiplicity of approaches and interpretations becomes completely obvious and understandable.

We do not consider the metaphor as some figurative tool that is located on the periphery of the language, and only in the case of loss of its metaphoricity penetrates its structure, forming the figurative meaning of the word. We understand the metaphor as a phenomenon of human thinking and human language, which bears a crucial function in cognition and description of the world. A metaphor is defined as a hidden comparison made by applying the name of one object to another and revealing one or another important feature of the second.

We understand the metaphor as a linguistic phenomenon associated with a certain way of being in the world. The scope of the metaphor is not limited to speech and cognition but extends to a person's attitude to being. The metaphor is fraught with the possibility of changing the meaning of familiar means and methods of reflecting on an object, and hence the possibility of a new look at what is already known, which is realized as revealing unknown properties and sides of this object. Thus, a new idea of a particular area appears, and the assimilation of this previously absent information expands, deepens, and ultimately rebuilds the entire traditional system of knowledge about the world.

A metaphor plays a big role in categorizing concepts. It shows how the new is known by man through the known. After all, concepts can be represented in a language using the means of nomination, including metaphors. That is why a new look at metaphor has led to the development of categories of cognitive metaphor.

Since the conceptual system of man is structured and determined by metaphors, therefore, in the paradigm of cognitive linguistics, metaphor is considered as one of the forms of conceptualization of the realities of the world, as well as the result of a cognitive process, on the basis of which new concepts are formed and expressed. Understanding the metaphor as a result of the correlation of two heterogeneous entities makes it possible to interpret it as a model for obtaining new knowledge about changes in society, through that old, static knowledge, which is human experience accumulated in various fields of activity.

The metaphor is associative, but at the same time, it correlates the new meaning with the existing experience. By its nature, the metaphor is creative and able to form new concepts and linguistic meanings, based on existing linguistic meanings. The metaphor is associated with both individual experience and cultural-linguistic experience, encoded in lexical and phraseological units of the language with emotive and cultural components. We gain new knowledge in the process of figurative metaphorization. This is especially true in cases where imagery is justified by any fixed cultural or other facts when the origin of the figurative-associative complex metaphors due to cultural and historical information.

The essence of the tropes is to compare the concept presented in the traditional use of the lexical unit, as well as the concept that is transmitted by the same unit in artistic speech when performing a stylistic function.

In contrast to the path, a figure is an act of using a nominative unit in order to enhance the expressiveness of speech. A figure is a syntactic construct designed to affect the listener and reader. If paths are forms of thought, then figures are forms of speech. An important function of the figure is to emphasize, highlight, strengthen one or another part of the statement.

The basis of the formation of the author's metaphor in the text is a non-standard spontaneous association, which can conditionally be described in terms of interference, understood in the physical sense. In this case, the contextual conditionality of the metaphor, which is a condition for the coherence of metaphor sources that interact, is of decisive importance in the process of redistribution of semantic attributes. 
A text is essentially a substance that organizes semiotic, in particular, linguistic structures that fall into its field of action in accordance with the author's intention. We can conclude that the emergence of an image should be considered as a process of complicating the connotation background within the framework defined by the figurative basis of the text - a metaphorical structure. This structure covers the entire text and allows the reader to determine the main parameters of figurative interaction between different semantic plans of the text.

Indirect communication is a meaningfully complicated communication in which understanding utterances involves considering the meanings that are absent in the utterance and require additional interpretation efforts by the addressee. The contrast between direct and indirect is not new in linguistics.

There are direct and figurative meaning observed in vocabulary, direct and indirect cases in morphology, and also direct and indirect addition in syntax. It is a global communicative category.

Direct communication is based on a system of units and the rules of their organization that can be coded. Direct communication is organized by attractors. The contrast of direct and indirect communication is not identical to the contrast of language - speech. Natural human language develops as a kind of struggle with indirect communication, as its overcoming. For example, in the formalized language of mathematics, there are only deictic signs that indicate certain meanings, and units of the natural language denote certain denotations, events, or phenomena. They are less direct than the characters of formalized codes because the addressee is involved in their decoding.

In linguistics and related sciences, there is an exceptionally large number of ways to streamline communication, overcoming entropy in it: various genre and rhetorical prescriptions, spelling, and orthoepic regulations (German, 2000). The metaphor traditionally combines two main functions: nomination (name) and characterization (expressive score). The peculiarity of the low, colloquialisms, slang metaphor is that in it, both the nomination and the characterization have value. A metaphorical nomination is a designation of new concepts with the help of old signs, i.e., units, already available in the common language system. Nomination metaphors acquire signs of terminoids: tail - 'academic debt,' cuisine - 'drum kit,' shoot - 'beg,' fish 'Swipe on the beach.' A metaphor-characterization is used to expressively rename well-known concepts: taxi - 'come,' write (scribble) the cart - 'communicate,' taxi 'solve.'

The empirical material of this study can be used in teaching both basic and special courses in language theory. At the same time, the results of the study can find application in the practice of teaching foreign language communication and in the practice of teaching translation, where the skillful use of expressive and visual means should be the subject of constant attention and care.

\section{Conclusion}

Among the diverse approaches to the study of metaphorizing processes, the leading one from the position of linguacultural study is the cognitive approach to metaphor as a way of classifying and systematizing physical and socio-cultural experience, considering it as a categorization process.

The metaphor is a kind of integrator, a means of tightening the components of the semantic, linguacultural space, and the world of reality behind it. This is a kind of rheumatic unity, which has a key characterizing value, including for the communicative organization of speech. Considering the metaphor as a rheumatic complex can allow us to approach the study of the process of metaphorizing based on the unity of its linguistic essence, discursive function, and textual implementation.

XLinguae, Volume 13 Issue 2, April 2020, ISSN 1337-8384, ISSN 2453-711X 
A systematic study and classification of metaphorical processes have identified a special role in metaphor research-oriented on metaphorical models (M-models) and metaphorizing models (M-models) as structure-forming dominants that form the metaphorical space of linguistic consciousness. A special role in the description of the metaphorizing model is given to the motivating metaphorical sign - the "metaphor symbol," which no less than the "source" and "target" of metaphorizing determines the semantic and linguistic and cultural characteristics of the entire process of metaphorizing.

The identification of figurative paradigms / metaphorical series makes it possible to see that each metaphor, having its own semantic and linguacultural features that stand behind them, is also associated with other members of the series, and this invariant core, uniting them, defines a certain direction of metaphorical meaning formation and determines its linguacultural significance.

Considering metaphors as a cognitive, speech-cognitive process allows us to see in it the role of a linguacultural integrator, a means of conceptual cohesion, the reunion of a mismatched linguacultural space.

The practical significance of the work lies in the possibility of using its results in lexicographic and translation practice, in the practice of university and school teaching, especially in university courses in the linguacultural study, intercultural communication, lexicology, in special courses and special seminars on semantics, problems of language and culture, in the practice of teaching English language as a foreign language, or in the preparation of undergraduate and graduate research papers.

\section{Bibliographic references}

ARISTOTLE. 1936. Poetics. // Antique theories of language and style.

ARNOLD, I.V. 2004. The style. Modern English. 6th ed. In: Flint: Nauka, 384 p.

ARUTYUNOVA, N.D. 1978. Functional types of linguistic metaphor, Ed. USSR Academy of Sciences. Ser. Lit. in. lang, vol. 37, n 4

DEMENTIEV, V.V. 2006. Indirect communication.

GERMAN, A.I. 2000. Linguasynergetics. - Barnaul,

KARASIK, V.A. - SLYSHKIN, G.G. 2002. Linguistic-vulgar concept as a unit of research // Methodological problems of cognitive linguistics: Scientific. ed. Voronezh State University, pp. 75 - 80.

KHARCHENKO V.K. 1991. Functions of the Metaphor: Study Guide. - Voronezh: Publishing House of Voronezh State University, $88 \mathrm{p}$.

KHONAMRI, F. - AHMADI, F. 2015. The effect of metacognitive strategy training and raising EFL learners' metacognitive knowledge on listening performance Open Access Indonesian Journal of Applied Linguistics, vol. 5, n. 1, pp. 18-27. ISSN 23019468.

LAGUTA, O. N. 2003. Metaphorology: theoretical aspects. Novosibirsk. Ch, 207 p.

LAKOFF, J. Thinking in the Mirror of Classifiers / 7 New in foreign linguistics. - L 988 ed. 23. pp. 12-53.

LAKOFF, J. - JOHNSON, M. 1990. Metaphors with which we live In: Theory of metaphor, pp. 387- 415.

LAKOFF, G. 1993. Contemporary theory of metaphor // Metaphor and thought Cambridge: Cambridge University Press, pp. 202 - 251.

LAKOFF, G. 1987. Women, fire and dangerous things: what categories reveal about the mind - Chicago: The University of Chicago Press, 593 p.

LOMONOSOV, M.V. 1955.Poly. volume. Op. Volume 7. Works before philology 1739-1758 $339 \mathrm{p}$.

MASLOVA, V.A. 2006. Introduction to cognitive linguistics, $314 \mathrm{p}$.

MOSKVIN, V.P. 2008. The correctness of Russian speech. - Rostov-on-Don,

MOSKVIN, V.P. 1996. Classification of Russian metaphors. In: Language personality: cultural concepts: Sat. scientific tr. — Volgograd: Change, 259 p. 
MOSKVIN, V.P. 2000. Russian metaphor: classification parameters In: Philological sciences, n. 2, pp. 66 - 74.

NIETZSCHE, F. 2006. Merry Science. Evil Wisdom In: Eshshmo, 528 p.

PETROV, B. B. 1990. The Ideas of Modern Phenomenology and Hermeneutics in the Linguistic Representation of Knowledge. In: Questions of Linguistics, n. 6, pp. 102 109.

SKLYAREVSKAYA, T.N. 1993. Metaphor in the language system. - SPb.: Nauka, $15 \mathrm{p}$.

TELIA, V. N. 1988. Metaphorization and its role in creating a linguistic picture of the world // Role of the human factor in language: Language and picture of the world / B.A. Serebrennikov, S. Kubryakova, V. I. Postovalova et al. In: Nauka, pp. 173 - 204. SEARLE, J. 1993, "Metaphor. Metaphor and Thought. 2-nd ed. Cambridge, 201 p.

Words: 4948

Characters: 32144 (17,86 standard pages)

Zhanna Ospanova

L.N.Gumilyov Eurasian National University

Foreign Philology Department

st. Satbayeva 2, Almaty district

Nur-Sultan city

Kazakhstan

erzhanuly03@list.ru

Tolybayeva Karima

L.N.Gumilyov Eurasian National University

Foreign Philology Department

st. Satbayeva 2, Almaty district

Nur-Sultan city

Kazakhstan

Associate Professor Nurkenova Saule

L.N.Gumilyov Eurasian National University

Foreign Philology Department

st. Satbayeva 2, Almaty district

Nur-Sultan city

Kazakhstan

Professor Kulyash Duisekova

L.N.Gumilyov Eurasian National University

Foreign Philology Department

st. Satbayeva 2, Almaty district

Nur-Sultan city

Kazakhstan

Gaukhar Baltabayeva

Kazakh State Women's Teacher Training Institute

Aiteke bi street 99

Almaty

Kazakhstan

erzhanuly03@list.ru 